\title{
Association between Hospitalist Productivity Payments and High-Value Care Culture
}

\author{
Reshma Gupta, MD, MSHPM'1,2,; Neil Steers, PhD ${ }^{1,4}$; Christopher Moriates, MD ${ }^{3,5}$; Michael Ong, MD, PhD ${ }^{1,4}$
}

'Department of Medicine, University of California Los Angeles, Los Angeles, California; ${ }^{2}$ UCLA Health, Los Angeles, California; ${ }^{3}$ Costs of Care, Boston, Massachusetts; ${ }^{4}$ Greater Los Angeles Veteran's Affairs Health System, Los Angeles, California; ${ }^{5}$ Dell Medical School at the University of Texas at Austin, Austin, Texas.

BACKGROUND: Given the national emphasis on affordability, healthcare systems expect that their clinicians are motivated to provide high-value care. However, some hospitalists are reimbursed with productivity bonuses and little is known about the effects of these reimbursements on the local culture of high-value care delivery.

OBJECTIVE: To evaluate if hospitalist reimbursement models are associated with high-value culture in university, community, and safety-net hospitals.

DESIGN, PATIENTS, AND SETTINGS: Internal medicine hospitalists from 12 hospitals across California completed a cross-sectional survey assessing their perceptions of high-value care culture within their institutions. Sites represented university, community, and safety-net centers with different performances as reflected by the Centers of Medicare and Medicaid Service's Value-based Purchasing (VBP) scores.

MEASUREMENT: Demographic characteristics and High-Value Care Culture Survey (HVCCS ${ }^{\mathrm{TM}}$ ) scores were evaluated using descriptive statistics, and associations were assessed through multilevel linear regression.

RESULTS: Of the 255 hospitalists surveyed, 147 (57.6\%) worked in university hospitals, 85 (33.3\%) in community hospitals, and 23 (9.0\%) in safety-net hospitals. Across all 12 sites, 166 (65.1\%) hospitalists reported payment with salary or wages, and 77 (30.2\%) with salary plus productivity adjustments. The mean HVCCS score was 50.2 (SD 13.6) on a 0-100 scale. Hospitalists reported lower mean HVCCS scores if they reported payment with salary plus productivity ( $\beta=-6.2,95 \% \mathrm{Cl}-9.9$ to -2.5$)$ than if they reported payment with salary or wages.

CONCLUSIONS: Hospitalists paid with salary plus productivity reported lower high-value care culture scores for their institutions than those paid with salary or wages. High-value care culture and clinician reimbursement schemes are potential targets of strategies for improving quality outcomes at low cost. Journal of Hospital Medicine 2019;14:16-21. Published online first October 31, 2018. (C) 2019 Society of Hospital Medicine rat he Centers of Medicare and Medicaid Services (CMS) has introduced new payment models that tie quality and value incentives to $90 \%$ of fee-for-service payments and provide $50 \%$ of Medicare payments through alternative payment models. ${ }^{1}$ The push toward value comes after productivity-based physician reimbursement (ie, fee for service) has been associated with poor quality care, including delayed diagnoses, complications, readmissions, increased length of stay, and high costs of care. ${ }^{2-5}$ The method of physician payment is widely believed to affect clinical behavior by incentivizing doing more, coding for more, and billing for more. ${ }^{6-7}$ Although payment systems may be used to achieve policy objectives, ${ }^{8}$ little is known about the association of different payment systems with the culture of delivering value-based care among frontline clinicians.

\footnotetext{
*Corresponding Author: Reshma Gupta, MD, MSHPM; E-mail: R44gupta@ ucla.edu; Telephone: 310-562-9096.

Additional Supporting Information may be found in the online version of this article.
}

Received: May 2, 2018; Revised: July 24, 2018; Accepted: August 11, 2018

() 2019 Society of Hospital Medicine DOI 10.12788/jhm.3084
Culture is defined as a system of shared assumptions, values, beliefs, and norms within an environment and has a powerful role in shaping clinician practice patterns. ${ }^{9-12}$ The culture within medicine currently contributes to the overuse of resources ${ }^{11,13}$ and a culture for improvement is correlated with clinical outcomes. A systematic review found a consistent association between positive organization culture and improved outcomes including mortality. ${ }^{14}$ Across health systems, institutions with high scores on patient safety culture surveys have shown improvements in clinical behaviors and patient outcomes. ${ }^{15-18}$

In this study, we aim to describe high-value care culture among internal medicine hospitalists across diverse hospitals and evaluate the relationship between physician reimbursement and high-value care culture.

\section{METHODS}

\section{Study Design}

This study is an observational, cross-sectional survey-based study of hospitalists from 12 hospitals in California between January and June 2016.

\section{Study Population}

A total of 12 hospitals with hospitalist programs in California 
were chosen to represent three types of hospitals (ie, four university, four community, and four safety net). Safety-net hospitals, which traditionally serve low-income and medically and socially vulnerable patients were defined as those in the top quartile (ie, greater than 0.5) of their Disproportionate Share Index (DSH), which measures Medicaid patient load. ${ }^{19-20}$

To select hospitals with varying value-based care performance, we stratified using CMS value-based purchasing (VBP) scores from fiscal year 2015; these scores have been used to adjust reimbursement for just over 3,000 hospitals in the VBP program of CMS. ${ }^{22,23} \mathrm{CMS}$ calculates the VBP total performance score as a composite of four domains: (1) clinical processes of care (20\% of total performance); (2) patient satisfaction (30\%); (3) patient outcomes, including mortality and complications (30\%); and (4) cost defined by Medicare payment per beneficiary $(20 \%) .{ }^{21}$ Established quality measures are based on data reported by participating hospitals and chart abstraction during 2011-2014. ${ }^{22}$ Although other clinical measures of care intensity have been used as proxies of value-based care, ${ }_{1}^{23,24}$ we used the measure of value that has been publically reported by the CMS VBP given its wide use and effects on reimbursements for $80 \%$ of hospitals in the CMS VBP program in $2015 .{ }^{25}$ We obtained institution-level data from the CMS VBP Program and Hospital Compare files. Each of the three types of hospitals represented institutions with low, middle, and high VBP performance (split in tertiles) as reported by the CMS VBP program. To increase the number of participants in tertiles with fewer hospitalists, a fourth hospital was selected for each hospital type.

We excluded individual hospitalists who primarily identified as working in subspecialty divisions and those who spent less than eight weeks during the last year providing direct patient care on inpatient internal medicine services at the studied in stitution.

\section{Measurement}

Hospitalists were asked to complete the High-Value Care Culture Survey (HVCCSTM), which measures the culture of value-based decision making among frontline clinicians. ${ }^{26}$ Similar to other validated surveys for the assessment of patient safety culture, ${ }^{27,28}$ the HVCCS can be used to identify target areas for improvement. The survey includes four domains: (1) leadership and health system messaging, (2) data transparency and access, (3) comfort with cost conversations, and (4) blame-free environment. This tool was developed by using a two-phase national modified Delphi process. It was evaluated at two academic centers to complete factor analysis and assess internal consistency, reliability, and validity among internal medicine hospitalists and residents. Validation included estimating product-moment correlation of overall HVCCS scores and domain scores with the CMS institutional VBP scores. HVCCS scores are standardized to a 0-100 point scale for each of the four domains and are then averaged to obtain an overall score. ${ }^{26}$

In the survey, value was defined as the quality of care provided to patients in relation to the costs required to deliver that care, and high-value care was defined as care that tried to maximize quality while minimizing costs. Quality was defined as the de- gree to which health services increased the likelihood of desired health outcomes that are safe, effective, patient centered, timely, equitable, and consistent with current professional knowledge. Cost was defined as the negative financial, physical, and emotional effects on patients and the health system. ${ }^{26}$

\section{Data Analysis}

We described the overall institutional mean high-value care culture and domain scores measured by the HVCCS, hospitalist demographics and training experiences, and hospital characteristics. We also described individual survey items. Descriptive statistics were stratified and compared on the basis of hospital type (ie, safety net, community, or university). We assessed the relationship between the clinician perception of reimbursement structure within their divisions and individually reported high-value care culture scores using bivariate and multilevel linear regression. We hypothesized that compared with hospitalists who were paid with salaries or wages, those who reported reimbursement with productivity adjustments may report lower HVCCS scores and those who reported reimbursement with quality or value adjustments may report higher HVCCS scores. We adjusted for physician- and hospital-level characteristics, including age, gender, and training track, and considered hospital type and size as random effects.

This study was approved by the Institutional Review Board at all 12 sites. All analyses were conducted using STATA ${ }^{\circledR} 13.0$ (College Station, Texas).

\section{RESULTS}

\section{Hospitalist Characteristics}

A total of $255(68.9 \%, 255 / 370)$ hospitalists across all sites completed the survey. Of these respondents, 135 were female (50.6\%). On average, hospitalists were 39 years of age (SD 6.8), trained in categorical tracks $(221 ; 86.7 \%)$, and had previously trained for 14.3 months at a safety-net hospital (SD 14.2). In total, 166 hospitalists $(65.1 \%)$ reported being paid with salary or wages, 77 (30.2\%) with salary plus productivity adjustments, and $12(4.7 \%)$ with salary plus quality or value adjustments. Moreover, 123 (48.6\%) hospitalists agreed that funding for their group depended on the volume of services they delivered. Community-based hospitalists reported higher rates of reimbursement with salary plus productivity $(47 ; 32.0 \%) \mathrm{com}$ pared with their counterparts from university-based $(24 ; 28.2 \%)$ and safety-net based programs (6; $26.1 \%)$. Among the three different hospital types, significant differences exist in hospitalist mean age $(P<.001)$, gender $(P=.01)$, and the number of months training in a safety-net hospital $(P=.02$; Table 1$)$.

\section{Hospital Characteristics}

Of the 12 study sites, four from each type of hospital (ie, safety-net based, community based, and university based) and four representing each value-based purchasing performance tertile (ie, high, middle, and low) were included. Eleven (91.7\%) sites were located in urban areas with an average DSH index of 0.40 (SD 0.23), case mix index of 1.97 (SD 0.28), and bed size of 435.5 (SD 146.0; Table 1). 
TABLE 1. Characteristics of Medical Centers ( $N=12)$ and Hospitalist Participants ( $N=255)$

\begin{tabular}{|c|c|c|c|c|c|}
\hline & $\begin{array}{c}\text { Overall } \\
(\mathrm{N}=255) \\
n(\%) \\
\text { Mean (SD) }\end{array}$ & $\begin{array}{l}\text { University } \\
(\mathrm{n}=147) \\
n(\%) \\
\text { Mean (SD) }\end{array}$ & $\begin{array}{l}\text { Community } \\
\qquad(n=85) \\
n(\%) \\
\text { Mean (SD) }\end{array}$ & $\begin{array}{c}\text { Safety-net } \\
(\mathrm{n}=23) \\
n(\%), \\
\text { Mean (SD) }\end{array}$ & $P$ Value \\
\hline \multicolumn{6}{|l|}{ Outcomes } \\
\hline HVCCS Overall Score & $50.18(13.60)$ & $51.71(14.69)$ & $47.31(11.57)$ & $50.58(11.71)$ & .06 \\
\hline Leadership and health system messaging & $65.35(15.59)$ & $67.43(16.90)$ & $64.02(13.34)$ & $56.84(10.53)$ & $.006 * *$ \\
\hline Blame-free environment & $50.74(21.42)$ & $51.70(20.67)$ & $46.62(21.77)$ & $59.78(22.28)$ & $.02 *$ \\
\hline \multicolumn{6}{|l|}{ Participant Level Characteristics } \\
\hline Age & $39.05(6.81)$ & $38.10(6.42)$ & $41.35(6.67)$ & $36.68(7.71)$ & $<.001 * * *$ \\
\hline Gender: Male & $125(49.41)$ & $83(56.85)$ & $31(36.47)$ & $11(50.00)$ & $.01 *$ \\
\hline Perception of Payment Structure & & & & & .80 \\
\hline Salary or wages only & $166(65.10)$ & $93(63.27)$ & $56(65.88)$ & $17(73.92)$ & \\
\hline Fee-for-service only & $0(0.00)$ & $0(0.00)$ & $0(0.00)$ & $0(0.00)$ & \\
\hline Salary + productivity & $77(30.20)$ & $47(31.97)$ & $24(28.24)$ & $6(26.09)$ & \\
\hline Salary + quality or value adj. & $12(4.71)$ & $7(4.76)$ & $5(5.88)$ & $0(0.00)$ & \\
\hline \multicolumn{6}{|l|}{ Institution-Level Characteristics } \\
\hline Bed Size & $435.50(145.99)$ & $545.75(81.32)$ & $339.50(124.88)$ & $421.25(164.83)$ & .13 \\
\hline Disproportionate Share Index ${ }^{a}$ & $0.40(0.23)$ & $0.43(0.05)$ & $0.12(0.10)$ & $0.64(0.10)$ & $<.001 * * *$ \\
\hline Case Mix Index & $1.97(0.28)$ & $2.16(0.19)$ & $1.99(0.25)$ & $1.77(0.26)$ & 0.19 \\
\hline
\end{tabular}

In multilevel regression modeling across all 12 sites, hospitalists from community-based hospitalist programs reported lower mean HVCCS scores $(\beta=-4.4,95 \% \mathrm{Cl}-8.1$ to -0.7$)$ (Table 2) than those from other hospital types.

\section{High-Value Care Culture Survey Scores}

The mean HVCCS score was 50.2 (SD 13.6), and mean domain scores across all sites were 65.4 (SD 15.6) for leadership and health system messaging, 32.4 (SD 22.8) for data transparency and access, 52.1 (SD 19.7) for comfort with cost conversations, and 50.7 (SD 21.4) for blame-free environment (Table 1). For the majority (two-thirds) of individual HVCCS items, more than $30 \%$ of hospitalists across all sites agreed or strongly agreed that components of a low-value care culture exist within their institutions. For example, over $80 \%$ of hospitalists reported low transparency and limited access to data (see Appendix I for complete survey responses).

Hospitalists reported different HVCCS domains as strengths or weaknesses within their institutions in accordance with hospital type. Compared with university-based and safetynet-based hospitalists, community-based hospitalists report- ed lower scores in having a blame-free environment (466, SD 21.8). Nearly $50 \%$ reported that the clinicians' fear of legal repercussions affects their frequency of ordering unneeded tests or procedures, and $30 \%$ reported that individual clinicians are blamed for complications. Nearly $40 \%$ reported that clinicians are uncomfortable discussing the costs of tests or treatments with patients and reported that clinicians do not feel that physicians should discuss costs with patients. Notably, community-based hospitalists uniquely differed in how they reported components of leadership and health system messaging. Over $60 \%$ reported a work climate or role modeling supportive of delivering quality care at lower costs. Only 48\%, however, reported success seen from implemented efforts, and $45 \%$ reported weighing costs in clinical decision making (Table 1, Appendix 1).

University-based hospitalists had significantly higher scores in leadership and health system messaging (67.4, SD 16.9) than community-based and safety-net-based hospitalists. They reported that their institutions consider their suggestions to improve quality care at low cost (75\%), openly discuss ways to deliver this care (64\%), and are actively implementing projects 
TABLE 2. Perception of Payment by Salary with Productivity Adjustments is Associated with Lower Institutional High-Value Care Culture Scores: Multilevel Regression Model among 12 Hospitalist Groups $(n=234)$

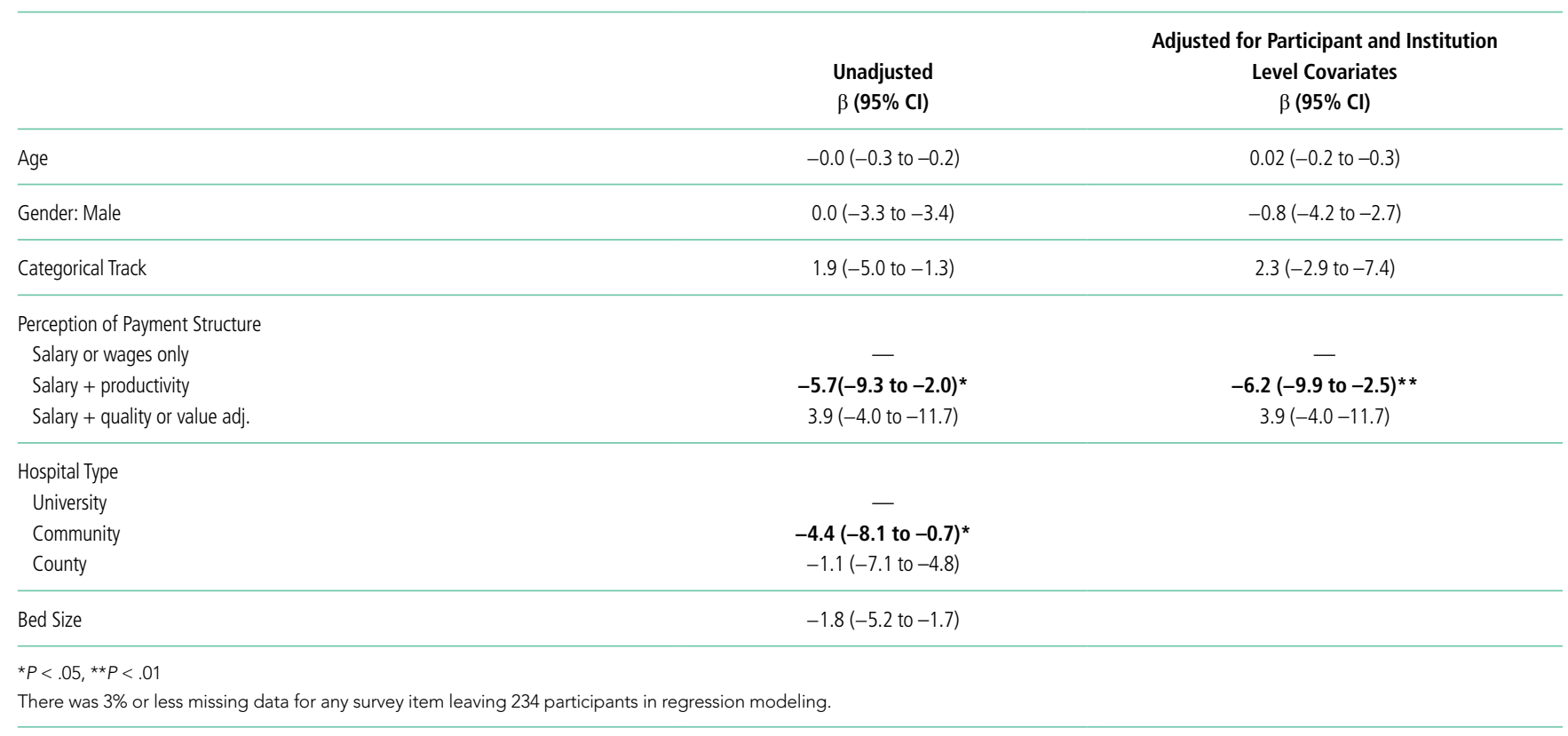

(73\%). However, only $54 \%$ reported seeing success from implemented high-value care efforts (Table 1, Appendix 1).

Safety-net hospitalists reported lower scores in leadership and health system messaging (56.8, SD 10.5) than university-based and community-based hospitalists. Few hospitalists reported a work climate $(26 \%)$ or role modeling (30\%) that is supportive of delivering quality care at low costs, openly discusses ways to deliver this care (35\%), encourages frontline clinicians to pursue improvement projects (57\%), or actively implements projects (26\%). They also reported higher scores in the blame-free environment domain (59.8, SD 22.3; Table 1; Appendix 1).

Productivity Adjustments and High-Value Care Culture In multilevel regression modeling, hospitalists who reported reimbursement with salary plus productivity adjustments had a lower mean HVCCS score $(\beta=-6.2,95 \% \mathrm{Cl}-9.9$ to -2.5$)$ than those who reported payment with salary or wages alone. Further multilevel regression modeling for each HVCCS domain revealed that hospitalists who reported reimbursement with salary plus productivity adjustments had lower scores in the leadership and health system messaging domain $(\beta=-4.9,95 \% \mathrm{Cl}-9.3$ to $-0.6)$ and data transparency and access domain ( $\beta=-10.7,95 \%$ $\mathrm{Cl}-16.7$ to -4.6$)$. No statistically significant difference was found between hospitalists who reported reimbursement with quality or value adjustments.

\section{DISCUSSION}

Understanding the drivers that are associated with a high-value care culture is necessary as payment models for hospitals transition from volume-based to value-based care. In this study, we found a meaningful association $(\beta=-6.2)$ between clinician reimbursement schemes and measures of high-value care culture. A six-point change in the HVCCS score would correspond with a hospital moving from the top quartile to the median, which represents a significant change in performance. The relationship between clinician reimbursement schemes and high-value care culture may be a bidirectional relationship. Fee for service, the predominant payment scheme, places pressure on clinicians to maximize volume, focus on billing, and provide reactive care. ${ }^{7,29}$ Conversely, payment schemes that avoid these incentives (ie, salary, wages, and adjustments for quality or value), especially if incentives are felt by frontline clinicians, may better align with goals for long-term health outcomes for patient populations and reduce excess visits and services. ${ }^{2-6,8,30-34}$ At the same time, hospitals with a strong high-value care culture may be more likely to introduce shared savings programs and alternative payment models than those without. Through these decisions, the leadership can play an important role in creating an environment for change. ${ }^{34}$ Similar to the study sites, hospitals in California have a higher percentage of risk-based payments than hospitals in other states $(>22 \%)^{35}$ and may also provide incentives to promote a high-value care culture or affect local physician compensation models.

Hospitals have options in how they choose to pay their clinicians, and these decisions may have downstream effects, such as building or eroding high-value care culture among clinicians or staff. A dose-response relationship between physician compensation models and value culture is plausible (salary with productivity < salary only < salary with value incentive). However, we did not find a statistically significant difference for salary with value incentive. This result may be attributed to the relatively small sample size in this study.

Hospitals can also improve their internal processes, organiza- 
tional structure, and align their institutional payment contracts with those that emphasize value over fee-for-service-based incentives to increase value in care delivery. ${ }^{36}$ The operation of hospitals is challenging when competing payment incentives are used at the same time, ${ }^{7}$ and leadership will likely achieve more success in improving a high-value care culture and value performance when all efforts, including clinician and institutional payment, are aligned. ${ }^{37-38}$

Enduring large systems redesign will require directing attention to local organizational culture. For the majority of individual HVCCS items, $30 \%$ or more hospitalists across all sites agreed or strongly agreed that components of low-value care culture exist within their institutions. This response demonstrates a lack of focus on culture to address high-value care improvement among the study sites. Division and program leaders can begin measuring culture within their groups to develop new interventions that target culture change and improve value. ${ }^{34}$ No single panacea exists for the value improvement of hospitalist programs in California across all hospital types and sites.

Unique trends, however, emerge among each hospital type that could direct future improvements. In addition to all sites requiring increased transparency and access to data, community-based hospitalists identified the need for improvement in the creation of a blame-free environment, comfort with cost conversations, and aspects of leadership and health system messaging. While a high proportion of these hospitalists reported a work culture and role modeling that support the delivery of quality care at low costs, opportunities to create open discussion and frontline involvement in improvement efforts, weigh costs into clinical decision making, and cost conversations with patients exist. We hypothesize that these opportunities exist because community-based hospitals create infrastructure and technology to drive improvement that is often unseen by frontline providers. University-based hospitalists performed higher on three of the four domains compared with their counterparts but may have opportunities to promote a blame-free environment. A great proportion of these hospitalists reported the occurrence of open discussion and active projects within their institutions but also identified opportunities for the improvement of project implementation. Safety-net hospitalists reported the need to improve leadership and health system messaging across most domain items. Further study is required to evaluate reasons for safety-net hospitalists' responses. We hypothesize that these responses may be related to having limited institutional resources to provide data and coordinated care and different institutional payment models. Each of these sites could identify trends in specific questions identified by the HVCCS for improvement in the high-value care culture. ${ }^{25}$

Our study evaluated 12 hospitalist programs in California that represent hospitals of different sizes and institutional VBP performance. A large multisite study that evaluates HVCCS across other specialties and disciplines in medicine, all regions of the country, and ambulatory care settings may be conducted in the future. Community-based hospitalist programs also reported low mean HVCCS scores, and further studies could better understand this relationship.
The limitations of the study include its small subgroup sample size and the lack of a gold standard for the measurement of high-value care. As expected, hospitalist groups among safety-net hospitals in California are small, and we may have been underpowered to determine some correlations presented by safety-net sites when stratifying by hospital type. Other correlations also may have been limited by sample size, including differences in HVCCS scores based on reimbursement and hospital type and the correlation between a blame-free environment and reimbursement type. Additionally, the field lacks a gold standard for the measurement of high-value care to help stratify institutional value performance for site selection. The VBP measure presents policy implications and is currently the best available measure with recent value data for over 3,000 hospitals nationally and representing various types of hospitals. This study is also cross-sectional and may benefit from the further evaluation of organizational culture over time and across other settings.

\section{CONCLUSION}

The HVCCS can identify clear targets for improvement and has been evaluated among internal medicine hospitalists. Hospitalists who are paid partly based on productivity reported low measures of high-value care culture at their institutions. As the nation moves toward increasingly value-based payment models, hospitals can strive to improve their understanding of their individual culture for value and begin addressing gaps.

\section{Acknowledgments}

The authors wish to thank Michael Lazarus, MD from the University of California Los Angeles; Robert Wachter, MD and James Harrison, PhD from the University of California San Francisco; Victoria Valencia, MPH from Dell Medical School at the University of Texas at Austin; Mithu Molla, MD from University of California Davis; Gregory Seymann, MD from the University of California San Diego; Bindu Swaroop, MD and Alpesh Amin, MD from University of California Irvine; Jessica Murphy, DO and Danny Sam, MD from Kaiser Permanente Santa Clara; Thomas Baudendistel, MD and Rajeeva Ranga, MD from Kaiser Permanente Oakland; Yile Ding, MD from California Pacific Medical Center; Soma Wali, MD from Los Angeles County/ OliveView UCLA Medical Center; Anshu Abhat, MD, MPH from the LA BioMed Institute at Los Angeles County/ Harbor-UCLA Medical Center; Steve Tringali, MD from Community Regional Medical Center Fresno; and Dan Dworsky, MD from Scripps Green Hospital for their site leadership and participation with the study.

Disclosures: Dr. Gupta is the Director of the Teaching Value in Healthcare Learning Network at Costs of Care. Dr. Moriates receives royalties from McGraw Hill for the textbook "Understanding Value-based Healthcare" outside of the submitted work and is the Director of Implementation at Costs of Care.

\section{References}

1. Burwell SM. Setting value-based payment goals-HHS efforts to improve U.S. Health care. N Engl J Med. 2015;372(10):897-899. doi: 10.1056/NEJMp1500445.

2. Riley GF, Potosky AL, Klabunde CN, Warren JL, Ballard-Barbash R. Stage at diagnosis and treatment patterns among older women with breast cancer: an $\mathrm{HMO}$ and fee-for-service comparison. JAMA. 1999;281(8):720-726. doi: 10.1001/jama.281.8.720.

3. Johnson LL, Becker RL. An alternative health-care reimbursement system-application of arthroscopy and financial warranty: results of a two-year pilot study. Arthroscopy. 1994;10(4):462-470; discussion 471. doi: 10.1016/ S0749-8063(05)80200-2. 
4. Cromwell J, Dayhoff DA, Thoumaian AH. Cost savings and physician responses to global bundled payments for Medicare heart bypass surgery. Health Care Financ Rev. 1997;19(1):41-57.

5. Edmonds C, Hallman GL. CardioVascular Care Providers. A pioneer in bundled services, shared risk, and single payment. Tex Heart Inst J. 1995;22(1):72-76.

6. Shen J, Andersen R, Brook R, et al. The effects of payment method on clinical decision-making: physician responses to clinical scenarios. Med Care. 2004;42(3):297-302. doi: 10.1097/01.mlr.0000114918.50088.1c.

7. Fernandopulle R. Breaking the fee-for-service addition: let's move to a comprehensive primary care payment model. Health aff blog. http://healthaffairs org/blog/2015/08/17/breaking-the-fee-for-service-addiction-lets-move-toa-comprehensive-primary-care-payment-model/. Accessed May 1, 2018; August 17, 2015

8. Centers for Medicare and Medicaid Services. Pioneer ACO final evaluation report. https://innovation.cms.gov/initiatives/Pioneer-ACO-Model/. Accessed March 8, 2018.

9. Ravasi D, Schultz M. Responding to organizational identity threats: exploring the role of organizational culture. AMJ. 2006;49(3):433-458. doi: 10.5465/ amj.2006.21794663.

10. Chen C, Petterson S, Phillips R, Bazemore A, Mullan F. Spending patterns in region of residency training and subsequent expenditures for care provided by practicing physicians for Medicare beneficiaries. JAMA. 2014;312(22):2385-2393. doi: 10.1001/jama.2014.15973.

11. Kanzaria HK, Hoffman JR, Probst MA, et al. Emergency physician perceptions of medically unnecessary advanced diagnostic imaging. Acad Emerg Med. 2015;22(4):390-398. doi: 10.1111/acem.12625

12. Dzeng $E$, Colaianni A, Roland $M$, et al. Influence of institutional culture and policies on do-not-resuscitate decision making at the end of life. JAMA In tern Med. 2015;175(5):812-819. doi: 10.1001/jamainternmed.2015.0295.

13. Colla $\mathrm{CH}$. Swimming against the current-what might work to reduce low-value care? N Engl J Med. 2014;371(14):1280-1283. doi: 10.1056/NEJMp1404503.

14. Braithwaite J, Herkes J, Ludlow K, Testa L, Lamprell G. Association between organizational and workplace cultures, and patient outcomes: systematic review. BMJ Open. 2017;7(11):e017708. https://bmjopen.bmj.com/content/ bmjopen/7/11/e017708.full.pdf. Accessed July 15, 2018. doi: 10.1136/bmjopen-2017-017708

15. Mardon RE, Khanna K, Sorra J, Dyer N, Famolaro T. Exploring relationships between hospital patient safety culture and adverse events. J Patient Saf. 2010;6(4):226-232. doi: 10.1097/PTS.0b013e3181fd1a00.

16. Singer S, Lin S, Falwell A, Gaba D, Baker L. Relationship of safety climate and safety performance in hospitals. Health Serv Res. 2009;44(2 Pt 1):399-421. doi: 10.1111/j.1475-6773.2008.00918.x.

17. Pettker CM, Thung SF, Raab CA, et al. A comprehensive obstetrics patient safety program improves safety climate and culture. Am J Obstet Gynecol. 2011;204(3):216.e1-216.e6. doi: 10.1016/j.ajog.2010.11.004.

18. Berry JC, Davis JT, Bartman T, et al. Improved safety culture and teamwork climate are associated with decreases in patient harm and hospital mortality across a hospital system. J Patient Saf. 2016. doi: 10.1097/ PTS.0000000000000251.

19. Chatterjee P, Joynt KE, Orav EJ, Jha AK. Patient experience in safety-net hospitals: implications for improving care and value-based purchasing. Arch Intern Med. 2012:172(16):1204-1210. doi: 10.1001/archinternmed.2012.3158.

20. Centers for Medicare and Medicaid Services, Disproportionate Share Hos- pital (DSH). https://www.cms.gov/Medicare/Medicare-Fee-for-Service-Payment/AcutelnpatientPPS/dsh.html. Accessed May 1, 2018

21. Centers for Medicare and Medicaid Services, Medicare Program. Hospital inpatient value-based purchasing program. Fed Regist. May 6, 2011;76(88):26496. http://www.gpo.gov/fdsys/pkg/FR-2011-05-06/pdf/201110568.pdf. Accessed May 1, 2018.

22. Center for Medicare and Medicaid Services, Medicare Program. https:// www.cms.gov/Medicare/Quality-Initiatives-Patient-Assessment-Instruments/hospital-value-based-purchasing/index.html?redirect=/Hospital-Value-Based-Purchasing/. Accessed May 1, 2018.

23. Sexton JB, Helmreich RL, Neilands TB, et al. The Safety Attitudes Questionnaire: psychometric properties, benchmarking data, and emerging research. BMC Health Serv Res. 2006;6:44. doi: 10.1186/1472-6963-6-44.

24. Singla AK, Kitch BT, Weissman JS, Campbell EG. Assessing patient safety culture. J Patient Saf. 2006;2(3):105-115. doi: 10.1097/01. jps.0000235388.39149.5a.

25. Centers for Medicare and Medicaid Services, HHS, Medicare Program. Hospital inpatient value-based purchasing program. Final rule. Fed Regist. 2011;76(26):490-547

26. Gupta R, Moriates C, Clarke R, et al. Development of a high-value care culture survey: a modified Delphi process and psychometric evaluation. BMJ Qual Saf. 2016:1-9. http://dx.doi.org/10.1136/bmjqs-2016-005612

27. Centers for Medicare and Medicaid Services. Medicare program; Hospital inpatient value-based purchasing program. Final rule. Fed Regist. 2011;76(88):26490-26547.

28. Arora A, True A, Dartmouth Atlas of Health Care. What Kind of Physician Will You Be? Variation in Health Care and Its Importance for Residency Training. Dartmouth Institute for Health Policy and Clinical Practice; 2012.

29. Berenson RA, Rich EC. US approaches to physician payment: the deconstruction of primary care. J Gen Intern Med. 2010;25(6):613-618. doi: 10.1007/ s11606-010-1295-z.

30. Rosenthal MB, Dudley RA. Pay-for-performance: will the latest payment trend improve care? JAMA. 1997;297(7):740-744. doi: 10.1001/jama.297.7.740

31. Smith M, Saunders SM, Stuckhardt L, McGinnis JM, eds. Best Care at Lower Cost: the Path to Continuously Learning Health Care in America. Washington, DC: National Academies Press; May 10, 2013.

32. Powers BW, Milstein A, Jain SH. Delivery models for high-risk older patients: Back to the Future? JAMA. 2016;315(1):23-24. doi: 10.1001/jama. 2015.17029

33. Sinsky CA, Sinsk TA. Lessons from CareMore: A stepping stone to stronger primary care of frail elderly patients. Am J Manag Care. 2015;3(2):2-3.

34. Gupta R, Moriates C. Swimming upstream: creating a culture of high value care. Acad Med. 2016:1-4. doi: 10.1097/ACM.0000000000001485

35. Berkeley Forum. California's delivery system integration and payment system. http://berkeleyhealthcareforum.berkeley.edu/wp-content/uploads/ Appendix-II.-California\%E2\%80\%99s-Delivery-System-Integration-and-Payment-System-Methodology.pdf. Accessed July 15, 2018; April 2013.

36. Miller HD. From volume to value: better ways to pay for health care. Health Aff. 2009:28(5):1418-1428. doi: 10.1377/hlthaff.28.5.1418.

37. Kahn CN, III. Payment reform alone will not transform health care delivery. Health Aff. 2009:28(2):w216-w218. doi: 10.1377/hlthaff.28.2.w216.

38. Sessums LL, McHugh SJ, Rajkumar R. Medicare's vision for advanced primary care: new directions for care delivery and payment. JAMA. 2016;315(24):26652666. doi: 10.1001/jama.2016.4472. 